\title{
Dietary patterns are associated with obesity in Japanese patients with schizophrenia
}

\author{
Norio Sugawara ${ }^{1 *}$, Norio Yasui-Furukori ${ }^{1}$, Yasushi Sato ${ }^{1,2}$, Manabu Saito ${ }^{1}$, Hanako Furukori ${ }^{3}$, Taku Nakagami ${ }^{4}$, \\ Masamichi Ishioka ${ }^{1}$ and Sunao Kaneko'
}

\begin{abstract}
Background: Obesity among patients with schizophrenia is a growing concern because being overweight is widely regarded as a major risk factor for cardiovascular disease and premature death. Dietary patterns have been suggested as one modifiable factor that may play a role in development of obesity. The objective of this study was to examine the association between dietary patterns and obesity among patients with schizophrenia in Japan.

Methods: We recruited patients $(n=338$ ) aged $44.0 \pm 13.2$ (mean \pm SD) years with a DSM-IV diagnosis of schizophrenia who were admitted to four psychiatric hospitals using a cross-sectional design. Diet was assessed with a validated brief-type self-administered diet history questionnaire (BDHQ). Dietary patterns from 52 predefined food groups were extracted by principal component analysis.

Results: A total of 61 subjects (18.0\%) were classified as obese. Three dietary patterns were identified: the healthy dietary pattern, the processed food dietary pattern, and the alcohol and accompanying dietary patterns. After adjusting for age and gender, patients within the high tertile of each healthy dietary pattern $(\mathrm{OR}=0.29,95 \% \mathrm{Cl}=0.13$ to 0.62$)$ and processed food dietary pattern $(\mathrm{OR}=0.44,95 \% \mathrm{Cl}=0.22$ to 0.89$)$ had a significantly lower risk for obesity compared with low tertile of dietary pattern.

Conclusions: Our findings suggest that dietary patterns, including higher intake of protein, fat, n-3 polyunsaturated fatty acids, n-6 polyunsaturated fatty acids, and vitamins, may be related to a decreased prevalence of obesity within patients with schizophrenia. Future longitudinal research exploring dietary patterns and obesity among patients with schizophrenia is warranted.
\end{abstract}

Keywords: Cross-sectional study, Schizophrenia, Dietary patterns, Obesity, Japanese

\section{Background}

Obesity is a growing concern because being overweight is widely regarded as a major risk factor for metabolic syndrome [1], cardiovascular disease [2], and premature death $[3,4]$. The prevalence of obesity among patients with schizophrenia is higher [5,6], and the life expectancy of patients with schizophrenia is approximately 15 years shorter for women and 20 years shorter for men, compared to the general population [7]. Although the mechanisms for this weight gain have not been entirely elucidated, dietary factors may be important in the development of obesity.

\footnotetext{
* Correspondence: nsuga3@yahoo.co.jp

${ }^{1}$ Department of Neuropsychiatry, Hirosaki University School of Medicine, 5

Zaifucho, Hirosaki City, Aomori 036-8562, Japan

Full list of author information is available at the end of the article
}

Diet consists of combinations of foods, and these individual components may have interactive or synergistic effects that make studying dietary factors in isolation difficult [8]. Dietary patterns that represent a combination of foods may be more strongly associated with disease risk than an individual food or nutrient [9-11]. Previous studies have reported that dietary patterns that are high in fruits, vegetables, and fibre might be associated with a reduced risk of obesity [12]. The European Prospective Investigation into Cancer and Nutrition (EPIC) Potsdam cohort found that dietary patterns that are high in fruit, and vegetables and low in high-fat dairy are associated with significantly less weight gain over a 4-year period [13]. In a US study, consuming a diet high in fruit, vegetables, and reduced-fat dairy, and low in meat, fast food, was associated with smaller gains in body mass index 
and waist circumference [14]. However, no study has investigated associations between dietary patterns and obesity among patients with schizophrenia.

In the present study, we examined the association between dietary patterns and obesity among patients with schizophrenia living in Japan. We hypothesised that dietary patterns consisting of high intake of vegetables and fish would be associated with a decreased risk of obesity.

\section{Methods}

\section{Participants}

This study was conducted between June 2011 and August 2011. The subjects included 338 outpatients (170 males and 168 females) who were diagnosed with either schizophrenia or schizoaffective disorder based on Diagnostic and Statistical Manual of Mental Disorders, fourth edition (DSM-IV) criteria at four psychiatric hospitals in Japan. The diagnoses were determined based upon medical records. The data collection for this study was approved by the Ethics Committee of the Hirosaki University School of Medicine (2011-039), and all subjects provided written informed consent before participating in this study.

\section{Procedure}

Subjects' demographic data (age and sex) were obtained from their medical records. Each subject's height and weight were measured, and the body mass index (BMI) was calculated as the individual's body mass divided by the square of their height $\left(\mathrm{kg} / \mathrm{m}^{2}\right)$. Participants were classified as being obese if their BMI was 30 or above.

Dietary habits during the preceding month were assessed using a validated brief self-administered diet history questionnaire (BDHQ) that contained questions about the consumption frequency of 56 foods and beverages and 9 dishes that are commonly consumed in the general Japanese population [15]. Dietary intake of energy and selected nutrients were estimated using an ad hoc computer algorithm for the 56 foods and beverages of the BDHQ and the Standard Tables of Food Composition in Japan [16,17].

\section{Statistical analyses}

The data were analysed using the PASW Statistics PC software for Windows, Version 18.0.0 (SPSS Inc., Chicago, IL, USA) and R 2.10.1. was used for the Cochran-Armitage trend test only [18]. We derived dietary patterns through a principal component analysis of energy-adjusted intake that used a density method for the 52 included food and beverage items (4 items that overlapped with others) [19]. We used eigen values, the scree test [20], and the interpretability of the factors to determine how many factors to retain. The factors each had eigen values greater than one. The scree plots dropped substantially after the third factor (from 2.39 to 2.05) and remained similar after the fifth factor (2.05 for the fourth and 1.94 for the fifth factor); thus, we retained three factors. The factor scores for each dietary pattern and for each individual were calculated by summing the food item intakes weighted by their factor loadings. The factor scores were categorised into tertiles.

Either Student's unpaired $t$-test (for the continuous variables) or the chi-square test (for categorical variables) was used to compare participants with and without obesity. Trend associations across the tertile categories of each dietary pattern were assessed using the Cochran-Armitage trend test for categorical variables and linear regression analysis for continuous variables, with ordinal values from 0 to 2 being assigned to the tertile categories of each dietary pattern. A logistic regression analysis was used to assess the relationships between dietary patterns and obesity. The model was adjusted for age and gender. A result with $p<0.05$ was considered to be significant.

\section{Results}

Characteristics of participants with and without obesity

The subjects were divided into two groups according to their BMI (subjects with obesity $\mathrm{BMI} \geq 30, \mathrm{n}=61$; subjects

Table 1 Characteristics of subjects with and without obesity

\begin{tabular}{|c|c|c|c|}
\hline & $\begin{array}{l}\text { Subjects } \\
\text { with obesity }^{a}\end{array}$ & $\begin{array}{l}\text { Subjects } \\
\text { without obesity }^{\text {b }}\end{array}$ & $\begin{array}{l}\mathrm{p} \\
\text { value }\end{array}$ \\
\hline Number of subjects & 61 & 277 & \\
\hline Age & $40.7 \pm 12.1$ & $44.7 \pm 13.3$ & $<0.05$ \\
\hline BMI & $34.0 \pm 3.4$ & $23.6 \pm 3.3$ & $<0.001$ \\
\hline Male (\%) & $29(47.5)$ & $141(50.9)$ & 0.635 \\
\hline \multicolumn{4}{|l|}{ Dietary intake } \\
\hline Energy (kcal) & $1807 \pm 1036$ & $1775 \pm 778$ & 0.780 \\
\hline Protein (g/1000 kcal) & $34.7 \pm 9.4$ & $37.1 \pm 7.7$ & $<0.05$ \\
\hline Carbohydrate (g/1000 kcal) & $142 \pm 27$ & $141 \pm 21$ & 0.752 \\
\hline Fat (g/1000 kcal) & $27.1 \pm 8.1$ & $28.0 \pm 7.1$ & 0.392 \\
\hline Dietary fibre (g/1000 kcal) & $5.18 \pm 2.38$ & $6.20 \pm 2.60$ & $<0.01$ \\
\hline Alcohol (g/1000 kcal) & $4.35 \pm 10.06$ & $2.89 \pm 8.14$ & 0.294 \\
\hline $\begin{array}{l}\mathrm{n}-3 \text { polyunsaturated fatty } \\
\text { acids ( } \mathrm{g} / 1000 \mathrm{kcal})\end{array}$ & $1.30 \pm 0.54$ & $1.42 \pm 0.49$ & 0.091 \\
\hline $\begin{array}{l}\mathrm{n}-6 \text { polyunsaturated fatty } \\
\text { acids (g/1000 kcal) }\end{array}$ & $5.19 \pm 1.84$ & $5.47 \pm 1.53$ & 0.218 \\
\hline Folate $(\mu \mathrm{g} / 1000 \mathrm{kcal})$ & $139 \pm 74$ & $162 \pm 82$ & $<0.05$ \\
\hline $\begin{array}{l}\text { Riboflavin (Vitamin B2) } \\
\text { (mg/1000 kcal) }\end{array}$ & $0.66 \pm 0.25$ & $0.67 \pm 0.21$ & 0.559 \\
\hline $\begin{array}{l}\text { Pyridoxine (Vitamin B6) } \\
\text { (mg/1000 kcal) }\end{array}$ & $0.55 \pm 0.19$ & $0.61 \pm 0.19$ & $<0.05$ \\
\hline $\begin{array}{l}\text { Cobalamin (Vitamin B12) } \\
\text { ( } \mathrm{gg} / 1000 \mathrm{kcal})\end{array}$ & $4.40 \pm 2.80$ & $4.95 \pm 2.76$ & 0.165 \\
\hline $\begin{array}{l}\text { Ascorbic acid (Vitamin C) } \\
\text { (mg/1000 kcal) }\end{array}$ & $41.5 \pm 30.3$ & $51.8 \pm 33.0$ & $<0.05$ \\
\hline
\end{tabular}

Abbreviation: $B M I$ body mass index.

${ }^{\mathrm{a}}$ Subjects with $\mathrm{BMI} \geq 30$.

bubjects with $\mathrm{BMI}<30$.

${ }^{\mathrm{C}}$ For continuous variables, non-paired t-tests were used; for categorical variables, chi-square tests were used. 
Table 2 Factor-loading matrix for major dietary patterns identified by principal component analysis ${ }^{a}$

\begin{tabular}{|c|c|c|c|}
\hline & $\begin{array}{l}\text { Healthy } \\
\text { dietary } \\
\text { pattern }\end{array}$ & $\begin{array}{l}\text { Processed } \\
\text { food } \\
\text { pattern }\end{array}$ & $\begin{array}{l}\text { Alcohol and } \\
\text { accompanying } \\
\text { dietary pattern }\end{array}$ \\
\hline Reduced fat milk and yogurt & 0.197 & - & - \\
\hline Milk and yogurt & - & 0.241 & -0.169 \\
\hline Chicken & - & 0.164 & - \\
\hline Ham/sausage/bacon & - & 0.332 & - \\
\hline Liver & - & 0.280 & 0.285 \\
\hline Squid/octopus/shrimp/shellfish & - & 0.272 & - \\
\hline Small fish with bones & 0.274 & - & - \\
\hline Canned tuna & - & 0.267 & - \\
\hline Dried fish/salted fish & - & 0.174 & - \\
\hline Oily fish & 0.209 & 0.154 & - \\
\hline Lean fish & 0.168 & - & - \\
\hline Tofu/atsuage ${ }^{b}$ & 0.399 & 0.157 & - \\
\hline Natto $^{c}$ & 0.369 & - & - \\
\hline Potatoes & 0.285 & 0.153 & - \\
\hline Pickled green leafy vegetables & 0.484 & - & - \\
\hline Other pickled vegetables & 0.238 & - & 0.164 \\
\hline Lettuces/cabbage (raw) & 0.751 & - & - \\
\hline Green leafy vegetables & 0.778 & -0.207 & - \\
\hline Cabbage/Chinese cabbage & 0.626 & - & - \\
\hline Carrots/pumpkin & 0.610 & - & - \\
\hline Japanese radish/turnip & 0.574 & - & 0.256 \\
\hline Other root vegetables & 0.618 & 0.179 & - \\
\hline Tomatoes & 0.510 & -0.249 & -0.210 \\
\hline Mushrooms & 0.664 & -0.150 & - \\
\hline Seaweeds & 0.650 & -0.269 & - \\
\hline Western-type confectioneries & - & 0.323 & -0.480 \\
\hline Japanese-type confectioneries & - & 0.255 & -0.404 \\
\hline $\begin{array}{l}\text { Rice crackers/rice cake/ } \\
\text { okonomiyaki }\end{array}$ & - & 0.236 & -0.331 \\
\hline Ice cream & -0.158 & - & -0.174 \\
\hline Citrus fruit & 0.177 & 0.327 & -0.189 \\
\hline $\begin{array}{l}\text { Persimmons/strawberries/ } \\
\text { kiwifruit }\end{array}$ & 0.344 & 0.281 & - \\
\hline Other fruit & 0.166 & 0.276 & -0.251 \\
\hline Mayonnaise & 0.413 & - & - \\
\hline Bread & - & 0.238 & -0.307 \\
\hline Buckwheat noodles & - & 0.254 & 0.278 \\
\hline Japanese wheat noodles & 0.179 & 0.347 & 0.408 \\
\hline Chinese noodles & -0.177 & 0.178 & 0.362 \\
\hline Pasta & - & 0.221 & 0.318 \\
\hline Green tea & 0.193 & - & - \\
\hline Black tea/oolong tea & - & 0.225 & 0.156 \\
\hline Cola drink/soft drink & -0.271 & - & - \\
\hline
\end{tabular}

Table 2 Factor-loading matrix for major dietary patterns identified by principal component analysis ${ }^{\text {a }}$ (Continued)

\begin{tabular}{llll}
\hline $100 \%$ fruit and vegetable juice & - & 0.171 & - \\
Rice & -0.195 & -0.762 & - \\
Miso soup & - & -0.340 & - \\
Sake & - & - & 0.270 \\
Beer & - & - & 0.460 \\
Shochu & - & - & 0.408 \\
Whisky & - & - & 0.356 \\
Wine & - & 0.150 & 0.321 \\
\hline
\end{tabular}

${ }^{a}$ Factor loading less than \pm 0.15 represented by a dash for simplicity. Omitted in the table were food items with factor loadings less than \pm 0.15 for all dietary patterns (Pork/beef, Egg, and Coffee).

${ }^{\mathrm{b}}$ Deep-fried tofu.

${ }^{\mathrm{C}}$ Fermented soybeans.

without obesity $\mathrm{BMI}<30, \mathrm{n}=277)$. The characteristics of both subject groups are listed in Table 1. Subjects with obesity were significantly younger; had higher BMIs; and had lower intake of protein, dietary fibre, folate, pyridoxine, and ascorbic acid. No other differences were observed.

Dietary patterns identified by principal component analyses We identified three dietary patterns by principal component analysis (Table 2). The first factor, which loaded heavily on vegetables, seaweeds, tofu, fruits, and fish, was labelled the "healthy" dietary pattern. The second factor, which had high loadings for ham/sausage/bacon, noodles, pasta, fruit, and confectioneries, was labelled the "processed food" dietary pattern. The third factor was characterised by high intake of alcoholic beverages, noodles, and liver; thus, it was termed the "alcohol and accompanying" dietary pattern. These three dietary patterns accounted for $10.2 \%, 4.9 \%$, and $4.6 \%$, respectively, of the variance in food intakes and explained $19.7 \%$ of the variance.

\section{Characteristics according to tertile categories of dietary pattern scores}

Table 3 shows the characteristics according to tertiles of the dietary pattern scores. The subjects with higher scores for the healthy dietary pattern were more likely to have lower BMIs and were less likely to be males. The healthy pattern was positively associated with intake of protein, fat, dietary fibre, n-3 polyunsaturated fatty acids (PUFA), n-6 PUFA, folate, riboflavin, pyridoxine, cobalamin, and ascorbic acid and was inversely associated with the intake of carbohydrates.

The subjects with higher scores for the processed food dietary pattern were more likely to have lower BMIs and less likely to be males. The processed food pattern was positively associated with intake of total energy, protein, fat, n-3 PUFA, n-6 PUFA, folate, riboflavin, pyridoxine, cobalamin, and ascorbic acid and was inversely associated with the intake of carbohydrates. The subjects with 
Table 3 Characteristics according to tertile categories of dietary pattern scores

\begin{tabular}{|c|c|c|c|c|c|c|c|c|c|c|c|c|c|}
\hline & \multirow[b]{2}{*}{ Total } & \multicolumn{4}{|c|}{ Healthy dietary pattern } & \multicolumn{4}{|c|}{ Processed food pattern } & \multicolumn{4}{|c|}{ Alcohol and accompanying dietary pattern } \\
\hline & & Low tertile & Middle tertile & High tertile & Trend $p^{a}$ & Low tertile & Middle tertile & High tertile & Trend $p^{a}$ & Low tertile & Middle tertile & High tertile & Trend $\mathrm{p}^{\mathrm{a}}$ \\
\hline Number of subjects & 338 & 112 & 113 & 113 & & 113 & 112 & 113 & & 112 & 113 & 113 & \\
\hline Age & $44.0 \pm 13.2$ & $42.9 \pm 12.1$ & $43.7 \pm 14.0$ & $45.3 \pm 13.4$ & 0.181 & $45.2 \pm 13.5$ & $43.5 \pm 12.2$ & $43.2 \pm 13.9$ & 0.253 & $43.3 \pm 13.5$ & $45.4 \pm 13.7$ & $43.2 \pm 12.2$ & 0.980 \\
\hline BMl & $25.5 \pm 5.2$ & $26.7 \pm 5.7$ & $25.6 \pm 5.3$ & $24.2 \pm 4.2$ & $<0.001$ & $26.3 \pm 5.0$ & $25.3 \pm 5.3$ & $24.8 \pm 5.3$ & $<0.05$ & $25.2 \pm 5.0$ & $25.1 \pm 4.7$ & $26.0 \pm 5.8$ & 0.294 \\
\hline Male (\%) & $170(50.3)$ & $71(63.4)$ & $60(53.1)$ & $39(34.5)$ & $<0.001$ & $63(55.8)$ & $59(52.7)$ & $48(42.5)$ & $<0.05$ & $47(42.0)$ & $48(42.5)$ & $75(66.4)$ & $<0.001$ \\
\hline \multicolumn{14}{|l|}{ Dietary intake } \\
\hline Energy (kcal) & $1781 \pm 829$ & $1679 \pm 872$ & $1877 \pm 822$ & $1788 \pm 785$ & 0.315 & $1656 \pm 591$ & $1670 \pm 626$ & $2014 \pm 1116$ & $<0.01$ & $1810 \pm 657$ & $1710 \pm 788$ & $1823=1005$ & 0.904 \\
\hline Protein (g/l000 kcal) & $36.6 \pm 8.1$ & $31.7 \pm 6.9$ & $36.8 \pm 7.7$ & $41.4 \pm 6.4$ & $<0.001$ & $33.7 \pm 7.3$ & $36.6 \pm 7.4$ & $39.6 \pm 8.3$ & $<0.001$ & $36.5 \pm 7.2$ & $37.3 \pm 7.7$ & $36.1 \pm 9.1$ & 0.721 \\
\hline $\begin{array}{l}\text { Carbohydrate } \\
\text { (g/l000kcal) }\end{array}$ & $141 \pm 22$ & $148 \pm 24$ & $139 \pm 21$ & $136 \pm 19$ & $<0001$ & $154 \pm 18$ & $138 \pm 21$ & $131 \pm 21$ & $<0001$ & $140 \pm 19$ & $146 \pm 20$ & $138 \pm 26$ & 0.408 \\
\hline Fat (g/1000 kcal) & $27.9 \pm 7.3$ & $25.6 \pm 8.0$ & $28.6 \pm 6.8$ & $29.4 \pm 6.6$ & $<0.001$ & $23.5 \pm 6.0$ & $28.2 \pm 6.8$ & $31.9 \pm 6.6$ & $<0.001$ & $30.9 \pm 6.8$ & $27.2 \pm 6.5$ & $25.6 \pm 7.6$ & $<0.001$ \\
\hline $\begin{array}{l}\text { Dietary fibre } \\
\text { (g/l000 kcal) }\end{array}$ & $6.02 \pm 2.59$ & $4.11 \pm 1.23$ & $5.49 \pm 1.00$ & $8.44 \pm 2.80$ & $<0.001$ & $5.74 \pm 3.08$ & $5.92 \pm 2.37$ & $6.38 \pm 2.21$ & 0.066 & $5.96 \pm 2.84$ & $6.11 \pm 2.47$ & $5.98=2.47$ & 0.948 \\
\hline Alcohol (g/l000kcal) & $3.16 \pm 8.52$ & $4.22 \pm 10.72$ & $3.14 \pm 8.54$ & $2.12 \pm 5.42$ & 0.065 & $2.49 \pm 6.06$ & $4.31 \pm 11.38$ & $2.68 \pm 7.19$ & 0.871 & $0.51 \pm 1.49$ & $0.80 \pm 2.18$ & $8.13 \pm 13.19$ & $<0.001$ \\
\hline $\begin{array}{l}\mathrm{n}-3 \text { polyunsaturated } \\
\text { fatty acids ( } \mathrm{g} / \mathrm{l} 000\end{array}$ & $1.40 \pm 0.50$ & $1.08 \pm 0.41$ & $1.43 \pm 0.41$ & $1.68 \pm 0.49$ & $<0.001$ & $1.22 \pm 0.42$ & $1.43 \pm 0.50$ & $1.54 \pm 0.52$ & $<0001$ & $1.48 \pm 0.52$ & $1.37 \pm 0.45$ & $1.35 \pm 0.52$ & $<0.05$ \\
\hline $\begin{array}{l}\mathrm{n}-6 \text { polyunsaturated } \\
\text { fatty acids ( } \mathrm{g} / \mathrm{l} 000\end{array}$ & $5.42 \pm 1.59$ & $4.83 \pm 1.82$ & $5.56 \pm 1.32$ & $5.85 \pm 1.44$ & $<0.001$ & $4.80 \pm 1.31$ & $5.54 \pm 1.74$ & $5.91 \pm 1.50$ & $<0.001$ & $5.60 \pm 1.57$ & $5.34 \pm 1.32$ & $5.32 \pm 1.84$ & 0.191 \\
\hline Folate ( $\mu \mathrm{g} / 1000 \mathrm{kcal})$ & $158 \pm 81$ & $99 \pm 34$ & $147 \pm 32$ & $228 \pm 96$ & $<0.001$ & $150 \pm 102$ & $153 \pm 69$ & $172 \pm 67$ & $<0.05$ & $157 \pm 94$ & $157 \pm 76$ & $161 \pm 74$ & 0.753 \\
\hline $\begin{array}{l}\text { Riboflavin } \\
\text { (Vitamin B2) } \\
\text { (mg/1000 kcal) }\end{array}$ & $0.67 \pm 0.22$ & $0.55 \pm 0.18$ & $0.68 \pm 0.19$ & $0.79 \pm 0.21$ & $<0.001$ & $0.60 \pm 0.23$ & $0.66 \pm 021$ & $0.75 \pm 0.18$ & $<0.001$ & $0.69 \pm 0.22$ & $0.68 \pm 0.22$ & $0.65 \pm 0.21$ & 0.145 \\
\hline $\begin{array}{l}\text { Pyridoxine } \\
\text { (Vitamin B6) } \\
\text { (mg/1000 kcal) }\end{array}$ & $0.60 \pm 0.19$ & $0.45 \pm 0.14$ & $0.59 \pm 0.12$ & $0.76 \pm 0.16$ & $<0.001$ & $0.54 \pm 0.19$ & $0.60 \pm 0.17$ & $0.67 \pm 0.18$ & $<0.001$ & $0.60 \pm 0.18$ & $0.60 \pm 0.19$ & $0.61 \pm 0.20$ & 0.879 \\
\hline $\begin{array}{l}\text { Cobalamin } \\
\text { (Vitamin BI2) } \\
(\mu \mathrm{g} / \mathrm{l000} \mathrm{kcal})\end{array}$ & $4.85 \pm 2.78$ & $3.47 \pm 2.42$ & $5.03 \pm 2.63$ & $6.03 \pm 2.67$ & $<0.001$ & $3.78 \pm 1.86$ & $4.95 \pm 2.63$ & $5.81 \pm 3.28$ & $<0.001$ & $4.89 \pm 2.56$ & $4.66 \pm 2.74$ & $4.99 \pm 3.02$ & 0.797 \\
\hline $\begin{array}{l}\text { Ascorbic acid } \\
\text { (Vitamin C) } \\
\text { (mg/l000 kcal) }\end{array}$ & $49.9 \pm 32.7$ & $29.2 \pm 20.2$ & $44.6 \pm 19.2$ & $75.8 \pm 36.2$ & $<0.001$ & $42.3 \pm 35.1$ & $46.6 \pm 27.7$ & $60.9 \pm 32.2$ & $<0.001$ & $51.4 \pm 35.4$ & $49.0 \pm 30.6$ & $49.4 \pm 32.1$ & 0.649 \\
\hline
\end{tabular}


higher scores for the alcohol and accompanying dietary pattern were more likely to have higher BMIs and to be males. The alcohol and accompanying pattern was positively associated with alcohol consumption and was inversely associated with intake of fat and n-3 PUFA.

\section{Odds ratio (OR) and $95 \%$ confidence intervals ( $\mathrm{Cls}$ ) for} obesity according to tertiles of dietary pattern scores

The odds ratios for obesity according to the tertile categories for each dietary pattern score are shown in Table 4. After adjusting for age and gender, patients within the high tertile of each healthy dietary pattern $(\mathrm{OR}=0.29,95 \% \mathrm{CI}=0.13$ to 0.62$)$ and processed food dietary pattern ( $\mathrm{OR}=0.44,95 \% \mathrm{CI}=0.22$ to 0.89 ) had a significantly lower risk for obesity compared with low tertile of dietary pattern. In the same condition, subjects in the high tertile for the alcohol and accompanying dietary pattern showed a tendency $(\mathrm{OR}=1.80,95 \% \mathrm{CI}=0.90$ to 3.59 ) toward a higher risk of obesity compared with the low tertile.

\section{Discussion}

Patients with schizophrenia have poorer diet quality (e.g., consume less dietary fibre and vitamins) than the general population [21,22], but few studies of the association between diet quality and obesity have been conducted in schizophrenic populations. Our results from a crosssectional study are the first evidence to suggest that a healthier dietary pattern may be instrumental in reducing obesity in patients with schizophrenia.

There have been two main types of approach used to extract dietary patterns. The first approach aims to calculate a graded score or index based on recommended diets or dietary guidelines [23]. This technique was called an a priori or hypothesis-oriented approach. The weakness of hypothesis-oriented approaches is that they focus on selected aspects of diet and do not consider the correlation structure of food and nutrient intakes. Consequently, such scores do not reflect the overall effect of diet in general but only the formal sum of not-adjusted single effects. The second approach, so called an a posteriori or exploratory approach, extracts dietary patterns from the data at hand. This approach ignores prior knowledge completely. Statistical exploratory methods that accomplish pattern extraction are principal component analysis and factor analysis, which are widely applied in nutritional epidemiology. Applied to food intake data, exploratory approaches aim to explain the total variation in intake of many foods or food groups.

We identified three major dietary patterns through principal component analysis: the healthy dietary pattern, the processed food pattern, and the alcohol and accompanying pattern. We hypothesised that dietary patterns consisting of a high intake of vegetables and fish would be associated with a decreased risk of obesity. In the present study, we found that subjects who consumed the healthy dietary pattern, characterised by a high intake of vegetables, seaweeds, tofu, fruits, and fish, showed significantly a lower risk for obesity. The processed food dietary pattern, characterised by a high intake of ham/sausage/bacon, noodles, pasta, fruit, and confectioneries, was also significantly associated with a lower risk of obesity. Because these two dietary patterns had different trends in total energy intake, just total energy intake alone does not uniquely cause obesity in schizophrenia. Although it remains unclear which components or nutritive factors might mediate the association between the observed dietary patterns and obesity among patients with schizophrenia, nutrients that are commonly included among these two dietary patterns,

Table 4 Odds ratio and $95 \%$ Cls for obesity according to tertiles of dietary pattern scores

\begin{tabular}{|c|c|c|c|c|c|}
\hline & No. of cases & Crude odds ratio & $\mathrm{p}$ value & Adjusted odds ratio & $\mathrm{p}$ value \\
\hline \multicolumn{6}{|c|}{ Healthy dietary pattern } \\
\hline Low tertile & 29 & Reference & & Reference & \\
\hline Middle tertile & 21 & $0.65(0.35-1.23)$ & 0.189 & $0.63(0.33-1.20)$ & 0.160 \\
\hline High tertile & 11 & $0.31(0.15-0.66)$ & $<0.01$ & $0.29(0.13-0.62)$ & $<0.01$ \\
\hline \multicolumn{6}{|c|}{ Processed food pattern } \\
\hline Low tertile & 27 & Reference & & Reference & \\
\hline Middle tertile & 19 & $0.65(0.34-1.25)$ & 0.199 & $0.62(0.32-1.20)$ & 0.153 \\
\hline High tertile & 15 & $0.49(0.24-0.98)$ & $<0.05$ & $0.44(0.22-0.89)$ & $<0.05$ \\
\hline \multicolumn{6}{|c|}{ Alcohol and accompanying dietary pattern } \\
\hline Low tertile & 18 & Reference & & Reference & \\
\hline Middle tertile & 16 & $0.86(0.42-1.79)$ & 0.689 & $0.91(0.44-1.91)$ & 0.804 \\
\hline High tertile & 27 & $1.64(0.84-3.19)$ & 0.145 & $1.80(0.90-3.59)$ & 0.095 \\
\hline
\end{tabular}

Abbreviation: $\mathrm{Cl}$ confidence interval.

Logistic regression model was adjusted for age and gender. 
such as higher intake of protein, fat, n-3 PUFA, n-6 PUFA, and vitamins, might affect our results. In addition, a higher intake of these two dietary patterns might be associated with socioeconomic status (education, family income) and life style (smoking, sleeping duration) [24-27].

The prevalence of obesity was markedly different in Japan as compared with Western countries [28-30] in general population. In contrast to previous results conducted among patients with schizophrenia in Western countries [31,32], we found that only $18 \%$ of our participants were obese. Differences of lifestyle and ethnicity between Japan and Western countries might affect the lower prevalence of obesity in our study.

The current study has several limitations. First, the cross-sectional nature of the study does not allow for causal assumptions about dietary patterns and the onset of obesity. Future longitudinal studies are needed to investigate these associations. Second, the dietary data were obtained using the BDHQ. Although the validity and reliability of our dietary questionnaire have been previously evaluated $[15,18]$, potential misclassification of dietary patterns may have affected our results. Third, several potential confounding factors, such as physical activity levels, socioeconomic status, life style, severity of schizophrenia, and antipsychotic medications, were not assessed in our study. Future studies adjusted for the above confounds are needed. Fourth, because all of the participants were volunteers who were interested in their health, they may not be representative of typical subjects with schizophrenia. Thus, patients who were not in the study may have different symptoms. This 'selection bias' must also be considered in studies of community populations. Finally, because our sample size was relatively small, we could not completely rule out beta error as the cause of the lack of a significant association between alcohol and accompanying dietary patterns and obesity.

\section{Conclusions}

Our findings suggest that dietary patterns with higher intakes of protein, fat, n-3 PUFA, n-6 PUFA, and vitamins may be related to a decreased prevalence of obesity. Intervention programs to change dietary patterns among patients with schizophrenia might be useful for treating obesity. Future research exploring dietary patterns and obesity among patients with schizophrenia is warranted, especially studies employing a longitudinal design.

\section{Competing interests}

The authors declare that they have no competing interests.

\section{Authors' contributions}

NS conceived the study, designed the study, conducted the statistical analysis, interpreted the data and wrote the initial draft of the manuscript. SK had full access to all of the data in the study and takes responsibility for the integrity of the data and the accuracy of the data analysis. NYF contributed to study design and assisted in drafting the manuscript. YS and HF completed initial survey construction, recruitment of participants. MS, TN, and MI participated in the data collection, and the interpretation of the results. All authors have approved the manuscript.

\section{Acknowledgments}

The authors would like to thank all coworkers for their skilful contributions to the data collection and management. Funding for this study was provided by a Grant-in-Aid for Young Scientists (B); The Ministry of Education, Culture, Sports, Science and Technology, Japan; the Karoji Memorial Fund for Medical Research (Grant B); and SENSHIN Medical Research Foundation.

\section{Author details}

'Department of Neuropsychiatry, Hirosaki University School of Medicine, 5 Zaifucho, Hirosaki City, Aomori 036-8562, Japan. ${ }^{2}$ Department of Psychiatry, Hirosaki-Aiseikai Hospital, Hirosaki, Japan. ${ }^{3}$ Department of Psychiatry, Kuroishi-Akebono Hospital, Kuroishi, Japan. ${ }^{4}$ Department of Psychiatry, Odate Municipal General Hospital, Odate, Japan.

Received: 18 December 2013 Accepted: 11 June 2014 Published: 20 June 2014

\section{References}

1. Zhang L, Zhang WH, Zhang L, Wang PY: Prevalence of overweight/obesity and its associations with hypertension, diabetes, dyslipidemia, and metabolic syndrome: a survey in the suburban area of Beijing, 2007. Obes Facts 2007, 4:284-289.

2. Marinou K, Tousoulis D, Antonopoulos AS, Stefanadi E, Stefanadis C: Obesity and cardiovascular disease: from pathophysiology to risk stratification. Int J Cardiol 2010, 138:3-8.

3. Adams KF, Schatzkin A, Harris TB, Kipnis V, Mouw T, Ballard-Barbash R, Hollenbeck A, Leitzmann MF: Overweight, obesity, and mortality in a large prospective cohort of persons 50 to 71 years old. N Engl J Med 2006, 355:763-778.

4. Pischon $T$, Boeing $H$, Hoffmann $K$, Bergmann $M$, Schulze MB, Overvad $K$, van der Schouw YT, Spencer E, Moons KG, Tjønneland A, Halkjaer J, Jensen MK, Stegger J, Clavel-Chapelon F, Boutron-Ruault MC, Chajes V, Linseisen J, Kaaks R, Trichopoulou A, Trichopoulos D, Bamia C, Sieri S, Palli D, Tumino R, Vineis $P$, Panico S, Peeters PH, May AM, Bueno-de-Mesquita HB, van Duijnhoven FJ, et al: General and abdominal adiposity and risk of death in Europe. N Engl J Med 2008, 359:2105-2120.

5. Limosin F, Gasquet I, Leguay D, Azorin JM, Rouillon F: Body mass index and prevalence of obesity in a French cohort of patients with schizophrenia. Acta Psychiatr Scand 2008, 118:19-25.

6. Fountoulakis KN, Siamouli M, Panagiotidis P, Magiria S, Kantartzis S, Papastergiou N, Shoretsanitis G, Pantoula E, Moutou K, Kouidi E, Deres S: Obesity and smoking in patients with schizophrenia and normal controls: a case-control study. Psychiatry Res 2010, 176:13-16.

7. Nordentoft M, Wahlbeck K, Hällgren J, Westman J, Osby U, Alinaghizadeh H, Gissler M, Laursen TM: Excess mortality, causes of death and life expectancy in 270,770 patients with recent onset of mental disorders in Denmark, Finland and Sweden. PLOS One 2013, 8:e55176.

8. Michels KB: Nutritional epidemiology-past, present, future. Int J Epidemiol 2003, 32:486-488.

9. Jacques PF, Tucker KL: Are dietary patterns useful for understanding the role of diet in chronic disease? Am J Clin Nutr 2001, 73:1-2.

10. Kant AK: Dietary patterns and health outcomes. J Am Diet Assoc 2004, 104:615-635.

11. Tucker K: Commentary: dietary patterns in transition can inform health risk, but detailed assessments are needed to guide recommendations. Int J Epidemiol 2007, 36:610-611.

12. Togo P, Osler M, Sørensen TI, Heitmann BL: Food intake patterns and body mass index in observational studies. Int J Obes Relat Metab Disord 2001, 25:1741-1751.

13. Schulz M, Nöthlings U, Hoffmann K, Bergmann MM, Boeing H: Identification of a food pattern characterized by high-fiber and low-fat food choices associated with low prospective weight change in the EPIC-Potsdam cohort. J Nutr 2005, 135:1183-1189.

14. Newby PK, Muller D, Hallfrisch J, Qiao N, Andres R, Tucker KL: Dietary patterns and changes in body mass index and waist circumference in adults. Am J Clin Nutr 2003, 77:1417-1425. 
15. Kobayashi S, Murakami K, Sasaki S, Okubo H, Hirota N, Notsu A, Fukui M, Date C: Comparison of relative validity of food group intakes estimated by comprehensive and brief-type self-administered diet history questionnaires against $16 \mathrm{~d}$ dietary records in Japanese adults. Public Health Nutr 2011, 14:1200-1211.

16. Science and Technology Agency: Standard Tables of Food Composition in Japan (in Japanese). Tokyo: Printing Bureau of the Ministry of Finance; 2005:1-508. 5th rev ed.

17. Science and Technology Agency: Standard Tables of Food Composition in Japan: Fatty Acid Section (in Japanese). Tokyo: Printing Bureau of the Ministry of Finance; 2005:1-321. 5th rev and enlarged ed.

18. Venables WN, Smith DM, the R Development Core Team: An Introduction to $R$, Notes on R: A Programming Environment for Data Analysis and Graphics Version 2.10.1. Bristol: Network Theory; 2009.

19. Willett W: Nutritional epidemiology. Oxford University Press: USA; 1998:20-23.

20. Cattell RB: The screen test for the number of factors. Multivariate Behav Res 1966, 1:245-276

21. McCreadie R, Macdonald E, Blacklock C, Tilak-Singh D, Wiles D, Halliday J, Paterson J: Dietary intake of schizophrenic patients in Nithsdale, Scotland: case-control study. BMJ 1998, 317:784-785.

22. Henderson DC, Borba CP, Daley TB, Boxill R, Nguyen DD, Culhane MA, Louie P, Cather C, Eden Evins A, Freudenreich O, Taber SM, Goff DC: Dietary intake profile of patients with schizophrenia. Ann Clin Psychiatry 2006, 18:99-105.

23. Gu Y, Scarmeas N: Dietary patterns in Alzheimer's disease and cognitive aging. Curr Alzheimer Res 2011, 8:510-519.

24. Engeset D, Alsaker E, Ciampi A, Lund E: Dietary patterns and lifestyle factors in the Norwegian EPIC cohort: the Norwegian women and cancer (NOWAC) study. Eur J Clin Nutr 2005, 59:675-684.

25. Park SY, Murphy SP, Wilkens LR, Yamamoto JF, Sharma S, Hankin JH, Henderson $\mathrm{BE}$, Kolonel LN: Dietary patterns using the food guide pyramid groups are associated with sociodemographic and lifestyle factors: the multiethnic cohort study. J Nutr 2005, 135:843-849.

26. Moreira P, Santos S, Padrão P, Cordeiro T, Bessa M, Valente H, Barros R, Teixeira V, Mitchell V, Lopes C, Moreira A: Food patterns according to sociodemographics, physical activity, sleeping and obesity in Portuguese children. Int J Environ Res Public Health 2010, 7:1121-1138.

27. Rezazadeh A, Rashidkhani B, Omidvar N: Association of major dietary patterns with socioeconomic and lifestyle factors of adult women living in Tehran, Iran. Nutrition 2010, 26:337-341.

28. Powell-Wiley TM, Ayers CR, de Lemos JA, Lakoski SG, Vega GL, Grundy S, Das SR, Banks-Richard K, Albert MA: Relationship between perceptions about neighborhood environment and prevalent obesity: data from the Dallas Heart Study. Obesity (Silver Spring) 2013, 21:E14-E21.

29. Befort CA, Nazir N, Perri MG: Prevalence of obesity among adults from rural and urban areas of the United States: findings from NHANES (2005-2008). J Rural Health 2012, 28:392-397.

30. Kolotkin RL, Corey-Lisle PK, Crosby RD, Swanson JM, Tuomari AV, Litalien GJ, Mitchell JE: Impact of obesity on health-related quality of life in schizophrenia and bipolar disorder. Obesity (Silver Spring) 2008, 16:749-754.

31. Chwastiak LA, Rosenheck RA, McEvoy JP, Stroup TS, Swartz MS, Davis SM Lieberman JA: The impact of obesity on health care costs among persons with schizophrenia. Gen Hosp Psychiatry 2009, 31:1-7.

32. Ministry of Health, Labor and Welfare, Japan: National Health and Nutrition Survey. http://www.mhlw.go.jp/bunya/kenkou/kenkou_eiyou_chousa.html.

doi:10.1186/1471-244X-14-184

Cite this article as: Sugawara et al: Dietary patterns are associated with obesity in Japanese patients with schizophrenia. BMC Psychiatry 2014 14:184

\section{Submit your next manuscript to BioMed Central and take full advantage of:}

- Convenient online submission

- Thorough peer review

- No space constraints or color figure charges

- Immediate publication on acceptance

- Inclusion in PubMed, CAS, Scopus and Google Scholar

- Research which is freely available for redistribution

Submit your manuscript at www.biomedcentral.com/submit
Biomed Central 